\title{
Automation of gearbox design
}

\author{
Marius Fürst $^{1}$ (D) J Joshua Götz ${ }^{1}$ (D) $\cdot$ Michael Otto $^{1}$ iD $\cdot$ Karsten Stahl $^{1}$
}

Received: 26 March 2021 / Accepted: 7 July 2021 / Published online: 13 September 2021

(c) The Author(s) 2021

\begin{abstract}
In order to respond to a shortened development time of today's transmission systems, the automation of certain steps in the design process is essential for ensuring an efficient development process. Computer-aided tools are widely used for analyzing given design configurations because standardized methods are available to evaluate the load carrying capacity of all key components of a simple gear train, namely bearings, shafts and gears. At an early stage of development, requirements and restrictions need to be synthesized to design concepts. During this step, engineers typically rely on their experience and proven practice. Design optimization usually is achieved through an iterative and time-consuming process of analyzing and tuning towards an optimization objective. In this paper a time-saving, automated and systematic method for the design of weight optimized helical gearboxes is proposed. The underlying method has been derived from both, norms and guidelines, which exist for the design and layout of shafts, bearings and gear wheel bodies. Starting with only few input parameters, a detailed shaft geometry with different diameter sections can be derived. A discrete set of values from standard tables and rolling bearing catalogs represents the method's framework for all realizable shaft diameters in each section. A mixed integer nonlinear optimization problem results from the interdependence between these distinct values. For this purpose, a systematic iterative approach has been developed and implemented in an established design program for gearbox systems. The algorithm uses the results drawn from an analytical calculation of the shaft load carrying capacity to directly adjust the shaft's diameter and length values. The dimensioning of the wheel body, the service life calculation of rolling element bearings and the selection of specific machine elements are embedded in a systematic sequence. As a result, the model is capable to work out a weight-optimized gearbox that consists of gear meshes, shafts and bearings, taking all three components into consideration at a time.
\end{abstract}

Marius Fürst

fuerst@fzg.mw.tum.de

1 Gear Research Centre (FZG), Department of Mechanical

Engineering, Technical University of Munich,

Boltzmannstraße 15, 85748 Garching, Germany 


\section{Automatisierung der Getriebeauslegung}

\section{Zusammenfassung}

Dank zunehmender Automatisierung des Produktentwicklungsprozesses heutiger Getriebesysteme können auch kurze Entwicklungszeiten effizient genutzt werden. In diesem Prozess ermöglichen standardisierte Rechenmethoden zur Bestimmung der Tragfähigkeit von Lagern, Wellen und Zahnrädern die rechnergestützte Bewertung aller Hauptkomponenten einer Getriebekonstruktion. Zu Beginn der Produktentwicklung müssen sämtliche Anforderungen und Randbedingungen in Getriebekonzepte überführt werden, wofür typischerweise auf Erfahrung und bewährtes Wissen zurückgegriffen wird. Eine Optimierung des Getriebekonzeptes hinsichtlich eines bestimmten Ziels wird anschließend durch einen iterativen, oft zeitaufwändigen, Prozess der Analyse und Feinabstimmung erreicht. In diesem Beitrag wird ein effizientes, automatisierbares und systematisches Verfahren zur Auslegung gewichtsoptimierter Stirnradgetriebe vorgestellt. Die Methode bindet gängige Normen und Richtlinien zur Auslegung und Gestaltung von Wellen, Lagern und Lagerungen sowie Radkörpern ein. Anhand weniger Eingangsparameter kann eine detaillierte, gestufte Wellengeometrie ermittelt werden. Das geometrische Grundgerüst zur Bestimmung der zulässigen Durchmesser eines jeden Wellenabschnitts besteht aus einer diskreten Wertemenge aus Normtabellen und Wälzlagerkatalogen. Die wechselseitige Abhängigkeit aller Wellenabschnitte führt zu einem gemischt-ganzzahligen nichtlinearen Optimierungsproblem, welches durch die Implementierung eines systematischen Iterationsprozesses in einem etablierten Auslegungsprogramm für Getriebesysteme gelöst wird. In den Optimierungsalgorithmus der Wellengeometrie fließen die Ergebnisse eines analytischen Tragfähigkeitsnachweises für Wellen ein. Hierbei wird in systematischer Reihenfolge die Radkörperdimensionierung, die Bestimmung der nominellen Lebensdauer von Wälzlagern und die Auswahl geeigneter Maschinenelemente verknüpft. Das beschriebene Vorgehen ermöglicht eine gewichtsoptimierte Getriebeauslegung durch die simultane Berücksichtigung von Verzahnungen, Wellen und Wälzlagern.

\section{Introduction}

The only way to keep pace with the trend toward ever shorter development times and, at the same time, constantly growing demands on technical systems is to consistently and efficiently integrate information technologies into the development process. Particularly thanks to the many years of development of transmission systems, a large number of empirical values and standards exist for the design of highperformance products. Depending on the phase in a product's development cycle, numerous calculation programs and simulation environments are available to evaluate designs. In early design phases, these usually focus only on individual machine elements or on the evaluation of a specific requirement, such as load capacity. The combination and interpretation of the available expertise remains the developer's task. In this context, the automation of certain sub-steps to ensure an efficient development process is essential to address the complexity of today's transmission systems adequately. Some commercial program systems, specifically tailored to the gear development process, were established in the industry: KISSsoft [24] and KISSsys [25], MASTA [34], FVA Workbench [18], and program systems from MDESIGN [26] and Romax [32]. These programs aim at supporting the developer in designing and analyzing through standardized calculation methods and system simulations. In addition, various research and company-owned software has been developed to cover one or more substeps in the development process. Hirt et al. $[19,20]$ de- scribe the integration of CAD/CAM systems into the design and optimization process of single-stage high-speed gear units. They show that the calculation results from several programs (gearing, plain bearings, bending vibration, etc.) can be transferred into a precise geometry model by standardizing the constructive configuration of the system. Standards and geometric specifications are taken into account in the design by tables and algorithms. Karayel et al. [23] established a design system for gearboxes that involves several stages of the design process, all consolidated in a single environment. Basic calculations required for dimensioning of machine elements like shafts, bearings, gears and keys can be processed consecutively with manual interaction. Dyla [15], Bansemir [14] and Parlow [31] developed a systematic approach for an explicit geometry synthesis of gear toothing. Based on performance and gear ratio specifications, its implementation in "GAP" [30] (German: Getriebeauslegungsprogramm) enables the generation of a topology, the design of gears and an approximate dimensioning of shafts. Starting from an initial design, various parameters can be changed and specified, which are then taken into account as new boundary conditions in a subsequent redesign. Interfaces to analysis programs for recalculation such as STplus [17] for cylindrical gear calculation and RIKOR [28] for load and deformation analysis of the entire gear system (consisting of gears, shafts, bearings and housing), are also part of GAP. Holder et al. [22] describe an approach for automated gear synthesis and positioning by using a central data model and graph-based design lan- 
guages to generate consistent, domain specific models for different engineering tools. For the design of shafts, they propose a division into several sections, which are linked to the associated components (bearings, gears). However, an automated method for determining the diameters and lengths of the individual sections of a shaft is not mentioned. In the aforementioned works, the dimensioning of machine elements and geometry synthesis of gearboxes is extensively studied, but no approach addresses the automation of all required steps to generate basically productionready assemblies consisting of shafts, bearings and gears. This study develops an automatable method for a detailed geometry synthesis and analysis of shafts in combination with the dimensioning of wheel bodies, rolling element bearings and selection of specific machine elements. The shaft model is derived from fundamental rules of machine design and is implemented in GAP.

\section{Method}

This section shows the developed models' structure and its underlying theory. It also covers the considerations made during the process of model derivation.

\subsection{Shaft geometry parameterization}

Almost all main components of a transmission interact directly with a gear shaft. Therefore, gear shafts can be regarded as the central machine element of a transmission. When designing a shaft, the requirements and dimensions imposed by the connected machine elements must be taken into account. In combination with design guidelines regarding function, manufacture, assembly and load, a generalized parameterization of the geometry of a gear shaft can be derived. For this purpose, the shaft is divided into several characteristic sections each of which is modeled by a different parameterization of the geometry (i.e. length and diameter of the section). Assembling several different sections in a specific order leads to a parametric representation of the shaft. We refer to this characteristic arrangement of the sections as the shaft skeleton. In the shaft skeleton, the qualitative dependence of the diameters on neighboring shaft sections is specified. For simple helical gearboxes without auxiliary function, such a generalized skeleton can already be defined on the basis of a few boundary conditions, such as the desired type of bearing (e.g. locating/non-locating bearing arrangement) and the function of the shaft in the gear (input, intermediate, or output shaft). Technically motivated requirements determine the qualitative structure of the shaft skeleton and form constraints of the optimization problem. Examples include an intended increase in the diameter of the shaft shoulders (from the shaft ends to the center) as a requirement for mountability and simplification of production. At the same time, this reflects an approximation to the idealized shaft contour with constant equivalent stress (e.g. paraboloid for central shear force application). For each of these sections, the respective diameter (e.g. load capacity requirement, available standard part diameters) as well as the length (e.g. width of standard parts, mounting chamfer) must be determined during the design process. To put it differently, this results in the following optimization problem, which has to be solved individually for each section of a shaft:

$$
\begin{array}{rlrl}
\text { minimize } & z & =1 / 4 \cdot \pi \cdot d^{2} \cdot l \cdot \rho+m_{\text {me }} \\
\text { such that } & d & \in \boldsymbol{R} \\
d & \in \mathcal{F} \\
& \boldsymbol{S}-\boldsymbol{S}_{\text {min }} & \geq \mathbf{0}
\end{array}
$$

Herein, a minimum of the objective function $\mathrm{z}$ (total mass) is sought, which is composed of the mass of the shaft section plus the mass of the related machine element $m_{\text {me }}$. Boundary conditions of this nonlinear mixed-integer optimization problem are that the shaft diameter has to be out of the feasible set of discrete values $\mathcal{F}$ (i.e. available standard part diameters) and within the range of stepping $\boldsymbol{R}$. Following basic design guidelines, $\boldsymbol{R}$ limits the maximum diameter step of two adjacent sections to $D / d \leq 1.4$ [27]. At the same time, all safety factors $S$ must exceed the given nominal value (e.g. shaft strength assessment, bearing service life, etc.). A schematic representation of the developed two-leveled shaft model used to obtain a detailed stepped shaft geometry at the end of an iterative design process is shown in Fig. 1.

Subsequently, all relevant section parameterizations will be outlined. The standards and calculation methods considered in the model are mentioned, and the type and position of the notches relevant for strength assessment of the shafts are described.

\subsubsection{Section "Load"}

Each gearbox has at least two connecting shafts for power input and output. Allowing a high degree of design freedom, key or splined shaft connections are widely used for positive shaft-hub connections. The standard DIN 748 [1] was intended to reduce this potentially high variability of shaft ends. By making use of this standard in the shaft model the feasible design space for lengths and diameters can be reduced. Additionally, a rough dimensioning of key and splined shaft connections is included as $[5,11,35]$ :

$p_{\mathrm{m}} \approx \frac{2 \cdot K_{\mathrm{A}} \cdot T_{\text {nom }}}{d_{\mathrm{m}} \cdot l_{\mathrm{s}} \cdot h_{\mathrm{s}} \cdot n \cdot \varphi} \leq p_{\text {allow }}$. 


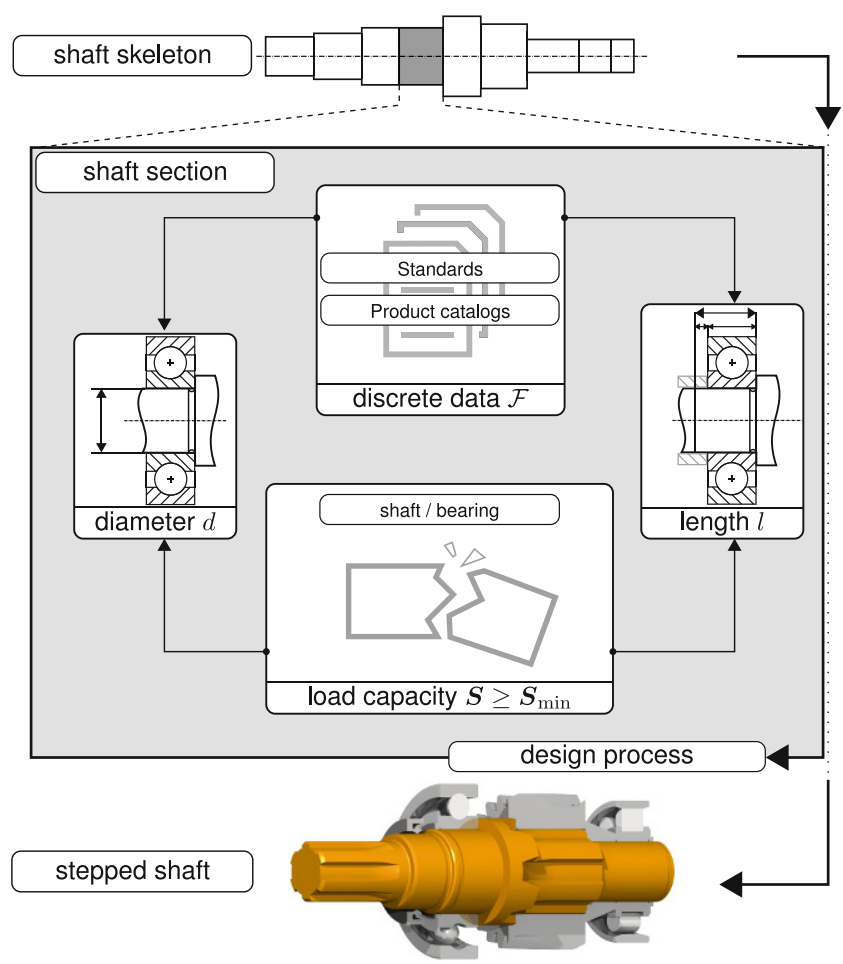

Fig. 1 Two-leveled shaft geometry model for designing stepped shafts (schematic)

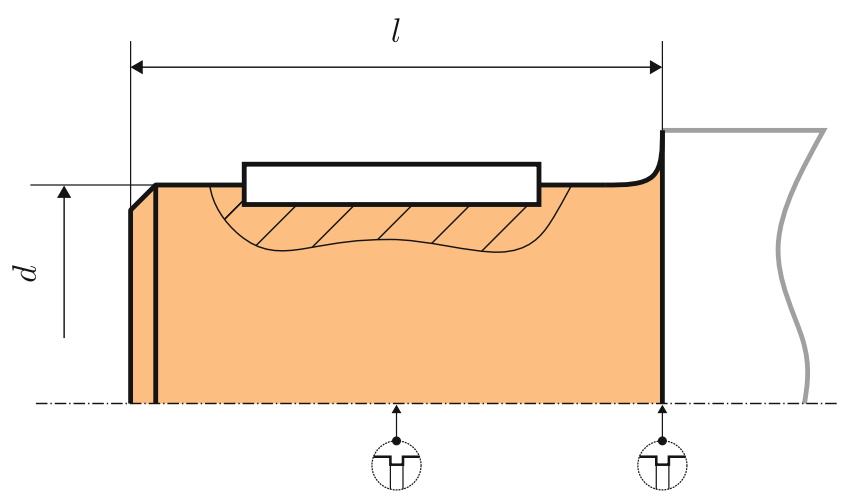

Fig. 2 Schematic representation of shaft section "Load" with two notches (key/spline and shoulder fillet)

The nearest possible standardized shaft end can then be selected. When calculating the load capacity of the shaft, notches at the center of the key or spline connection and at the shaft shoulder fillet are analyzed. Fig. 2 shows a schematic representation of the parameterized section "Load".

\subsubsection{Section "Radial shaft seal"}

The dimensions of radial shaft seals are standardized in DIN 3760 [3]. For damage-free mounting and safe function fulfillment during operation, a lead-in chamfer and running surface widening for seal rings with both protective and

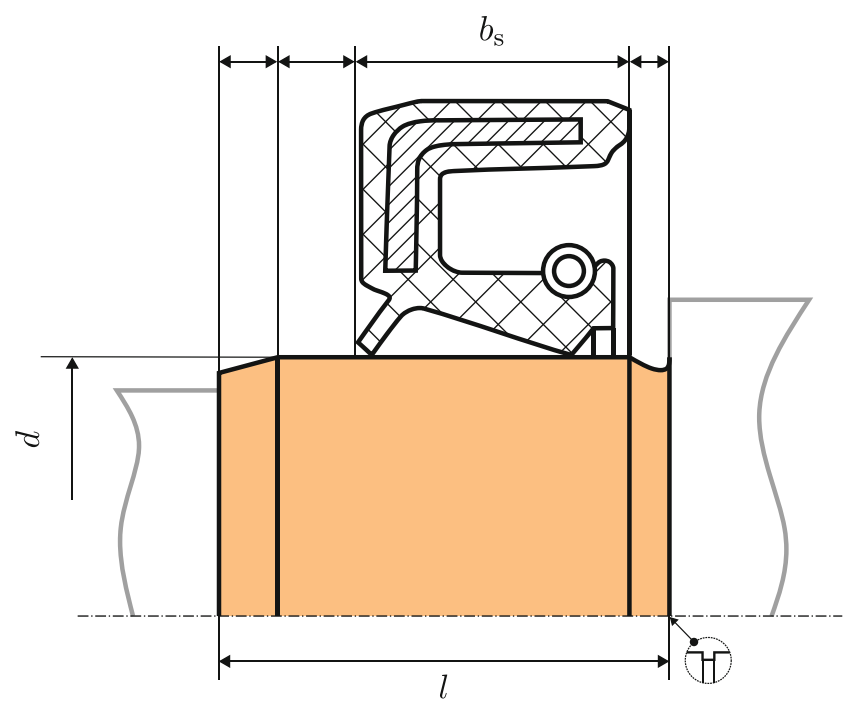

Fig. 3 Schematic representation of shaft section "Radial shaft seal" with one notch (undercut)

sealing lips must be provided on the shaft [3]. For a production-ready design, an undercut of shape E [6] on the shaft shoulder is taken into account as manufacturing tool runout. See Fig. 3 for a graphical representation of the chosen parameterization for shaft sealing sections. For this section, one notch at the shaft shoulder (undercut) is analyzed during the dimensioning process.

\subsubsection{Section "Axial lock"}

There are various options for axially locking bearings and gears. The most common are circlips [9] and lock nuts [7]. For both options a parametric representation of the related shaft section has been derived, see Fig. 4.

The lock nut section takes into account a thread undercut of shape A [13] and a thread protrusion with lead-in chamfer, represented as diameter-dependent factor. The dimensions of the lock nut and lock washer are specified in standard tables $[7,10]$. The keyway for engagement of lock washers should have a distance to the shaft shoulder so that the increase of the notch effect due to the coincidence of several notches is reduced. To sum it all up, the length of the section is given by $l=0.05 \cdot d+b_{1}+\max \left\{g_{2}, b_{3} / 2\right\}$. Two notches are taken into account: the thread (modeled as a V-notch) and the thread undercut with dimensions obtained from [4] and [13] respectively. The geometry of the circlip section is composed of the width of the rectangular groove and the minimum collar width according to the standard [9]. The groove is the only notch for the evaluation of load capacity at this section. 
Fig. 4 Schematic representation of shaft sections "Lock nut" and "Circlip" with notches (thread and thread undercut/rectangular groove)

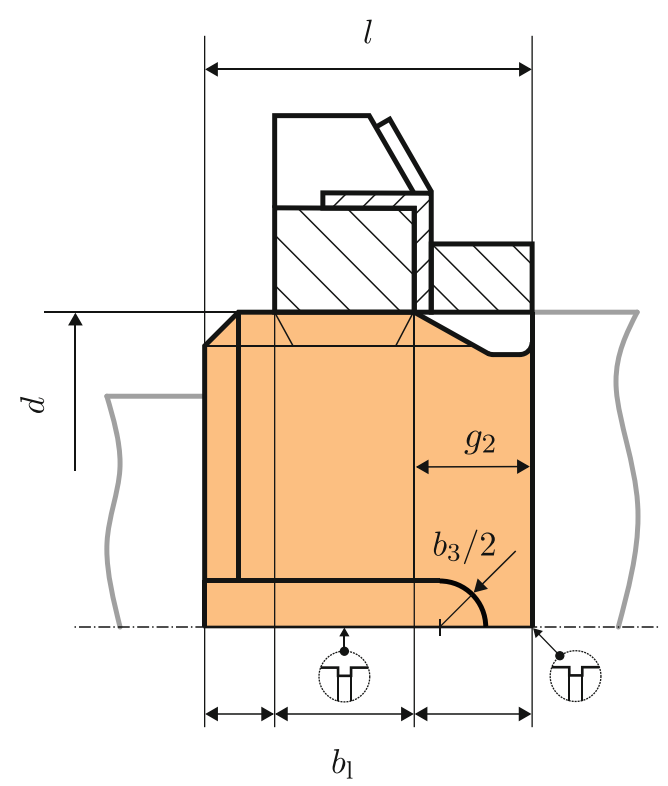

\subsubsection{Section "Rolling bearing"}

Rolling bearings are used in most gear applications to transmit forces and to define position of gear elements moving relative to each other. Standardized methods can be used to calculate the load capacity and service life expectancy. In this study, the selection of suitable rolling bearings is based on the calculation of the expanded modified rating life ac-

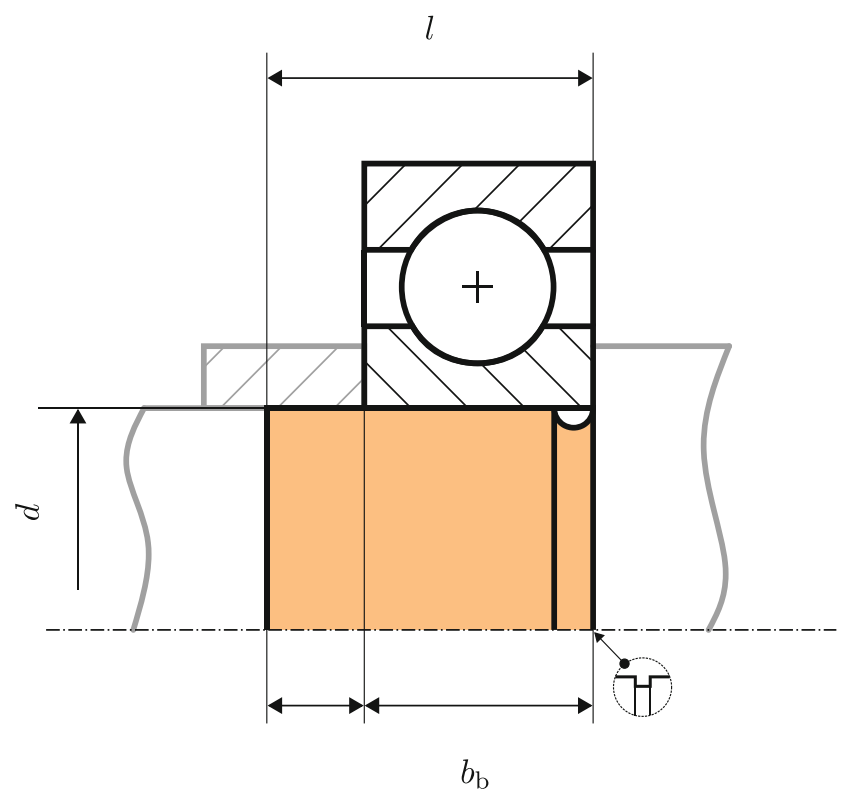

Fig. 5 Schematic representation of shaft section "Rolling bearing" with one notch (undercut) cording DIN ISO 281 [8], which must exceed the specified nominal value:

$L_{n \mathrm{~m}}=a_{1} \cdot a_{\mathrm{ISO}} \cdot L_{10} \geq L_{n \mathrm{~m}, \mathrm{nom}}$.

Depending on the bearing type and arrangement, rolling element bearings require a specific positioning approach. In addition, the adjacent shaft sections may be of different characteristics (lock nut, gear, etc.), which results in the chosen section parameterization shown in Fig. 5.

On one side, the rolling bearing limits the shaft section (e.g. for an adjacent shaft shoulder or sleeve), on the other side there is the possibility of providing a distance washer for adjustment, a free shaft end, or a centering for a sleeve to the adjacent lock nut. For all combinations it is ensured that the inner ring is supported over the entire width except the undercut at the circumference. Depending on the position of the section in the skeleton, the overhanging length of the section can be specified differently. Distance washers are assumed to have a constant width of $0.5 \mathrm{~mm}$, centerings are expressed parametrically: $l=b_{\mathrm{b}}+0.05 \cdot d$. This shaft section contains a maximum of one notch, provided that there is a shaft shoulder towards one side. In the load capacity calculation this undercut of shape F [6] is considered.

\subsubsection{Section "Gear wheel"}

Assuming sufficient dimensioning of the gearing, the connection of the gear wheel to the shaft via keys or splines must also be ensured, see Eq. (2). The shaft section of a gear is mainly defined by the designed gear width or the specified hub geometry of the gear body. A connection with adjacent shaft sections is considered via a projection of the 


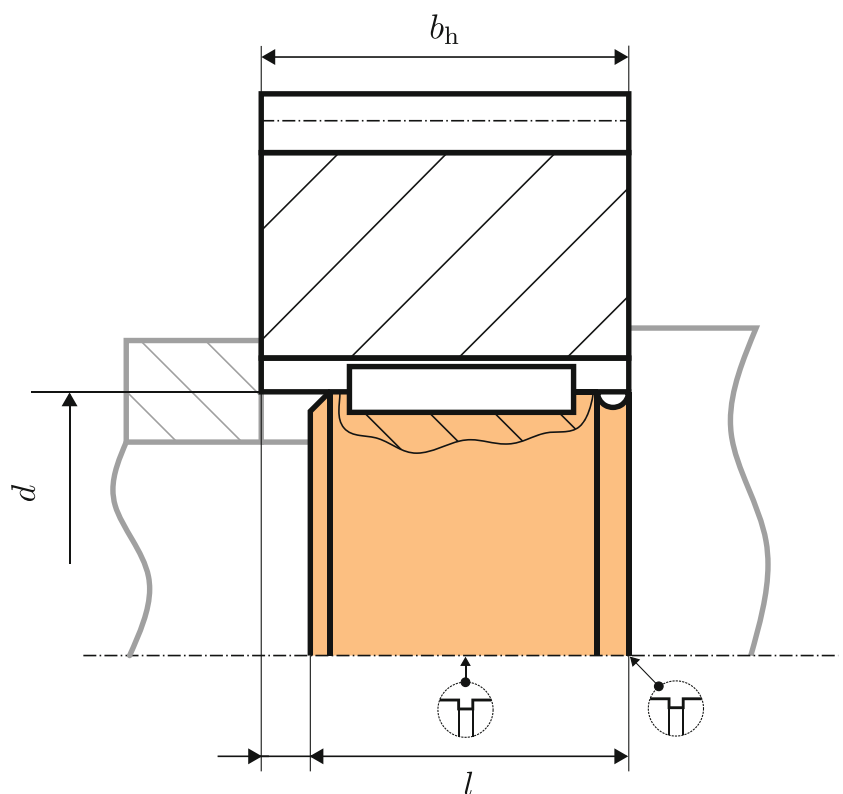

Fig. 6 Schematic representation of shaft section "Gear wheel" with two notches (key/spline and undercut)

hub beyond the section. This is represented in the model by a diameter-dependent factor: $l=b_{\mathrm{h}}-0.05 \cdot d$. The chosen parameterization of a gear wheel section is shown in Fig. 6. Two notches are taken into account in the load capacity calculation: a key/spline connection and an undercut of shape F [6] at the shaft shoulder.

\subsubsection{Section "Spacer"}

The shaft sections described so far are characterized by the fact that they always contain a machine element and can thus be dimensioned using the available standard part dimensions and design recommendations. However, a gear shaft also contains sections on which no machine elements are arranged on and are used, for example, to maintain distances between machine elements. This gap in the shaft skeleton is closed by a spacer section, see Fig. 7 .

On the one hand, the spacer can contain a sleeve and thus connect two shaft sections of different machine elements; on the other hand, it can also take the shape of a shaft shoulder for axial fixing and positioning of two adjacent machine elements. The length of this section results directly from the position of the adjacent machine elements and their dimensions. The diameter of a spacer section should on the one hand have the minimum value of the shaft shoulder contained in bearing catalogs, and on the other hand provide a sufficiently large contact surface for a gear pushed on from the other side. A factor of $D / d=1.2$ was defined for this purpose. Based on this value, the next larger value of the standard number series R40 [2] is selected as the diameter of the shaft shoulder. The spacer section contains a notch only if it is realized in the form of a sleeve and is represented as an undercut of shape E [6].

\subsubsection{Skeleton "Input/output shaft"}

For drive shafts, the following characteristic arrangement of shaft sections was selected for a symmetrically mounted pinion in a locating/non-locating arrangement, see Fig. 8: load (1), sealing ring (2), axial lock (3), bearing (4), spacer (5), gear (6), spacer (7), bearing (8) and axial lock (9).

The spacers serve to maintain distances between the bearings and the gear wheel or from the gear wheel to the gear housing. For a locating/non-locating bearing arrangement, both bearing inner rings must be axially secured. One
Fig. 7 Schematic representation of shaft section "Spacer" with one notch (undercut)

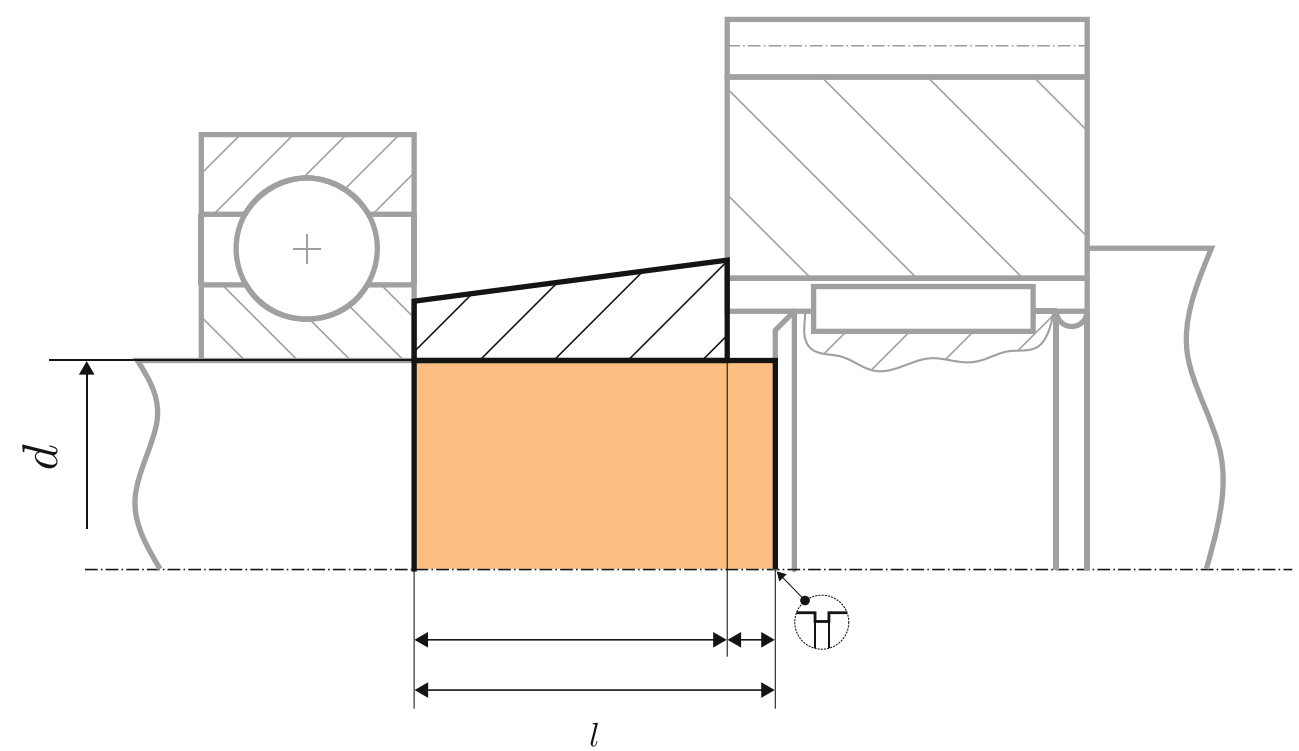


Fig. 8 Schematic representation of skeleton "Input/output shaft"

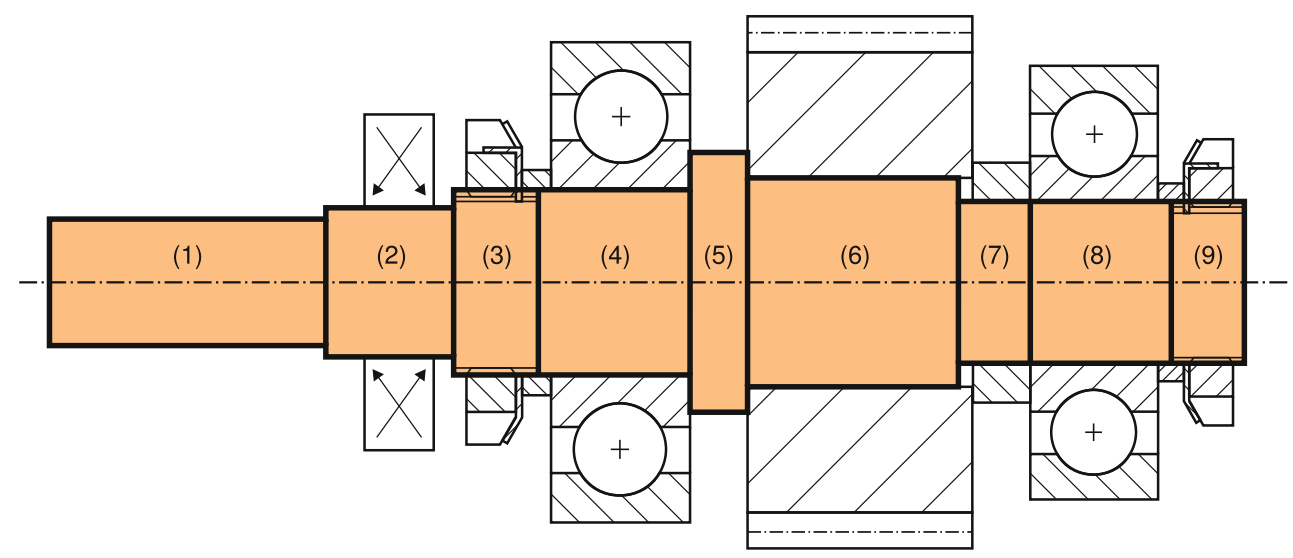

of the two axial locking devices can also be used to secure the pinion, thereby shifting the notch effect of the rectangular groove for circlips or of the thread for locknuts to the less stressed areas of the shaft. In addition, one of the two spacers (5) is to be designed as a shaft shoulder so that the pinion and bearing can be supported accordingly. Spacer (7), on the other hand, is designed as a sleeve. The locating bearing support (4) is arranged close to the shaft coupling (1) to ensure precise guidance. Because of the preceding sealing ring, the shaft diameters tend to be larger at this point than at the second bearing point (8). This can be used for the higher loaded locating bearing, since the load capacity typically increases with the diameter. If the pinion teeth are not to be cut into the shaft, it is advisable to axially locate the pinion together with the non-locating bearing (8). This is because the relatively small root diameter of a pinion restricts the maximum diameters of the sections further out. The selected shaft skeleton of the output shaft matches the structure of the input shaft skeleton.

\subsubsection{Skeleton "Intermediate shaft"}

In contrast to the input shaft, there is no additional torque input or output on the intermediate shaft. For a locating/nonlocating bearing arrangement, the following characteristic arrangement of the shaft sections was chosen, see Fig. 9: axial lock (1), bearing (2), spacer (3), gear (4), spacer (5), gear (6), spacer (7), bearing (8), axial lock (9).

A design with a central shaft shoulder was selected for axial locating of both bearing inner rings and gears. One bearing and one gear each can then be mounted with the same axial locking element. The axial lockings are located in non-critical areas on the shaft without impact of torque. The spacers (3) and (7) are designed as sleeves, but can also be designed as shaft shoulders if the toothing on the
Fig. 9 Schematic representation of skeleton "Intermediate shaft"

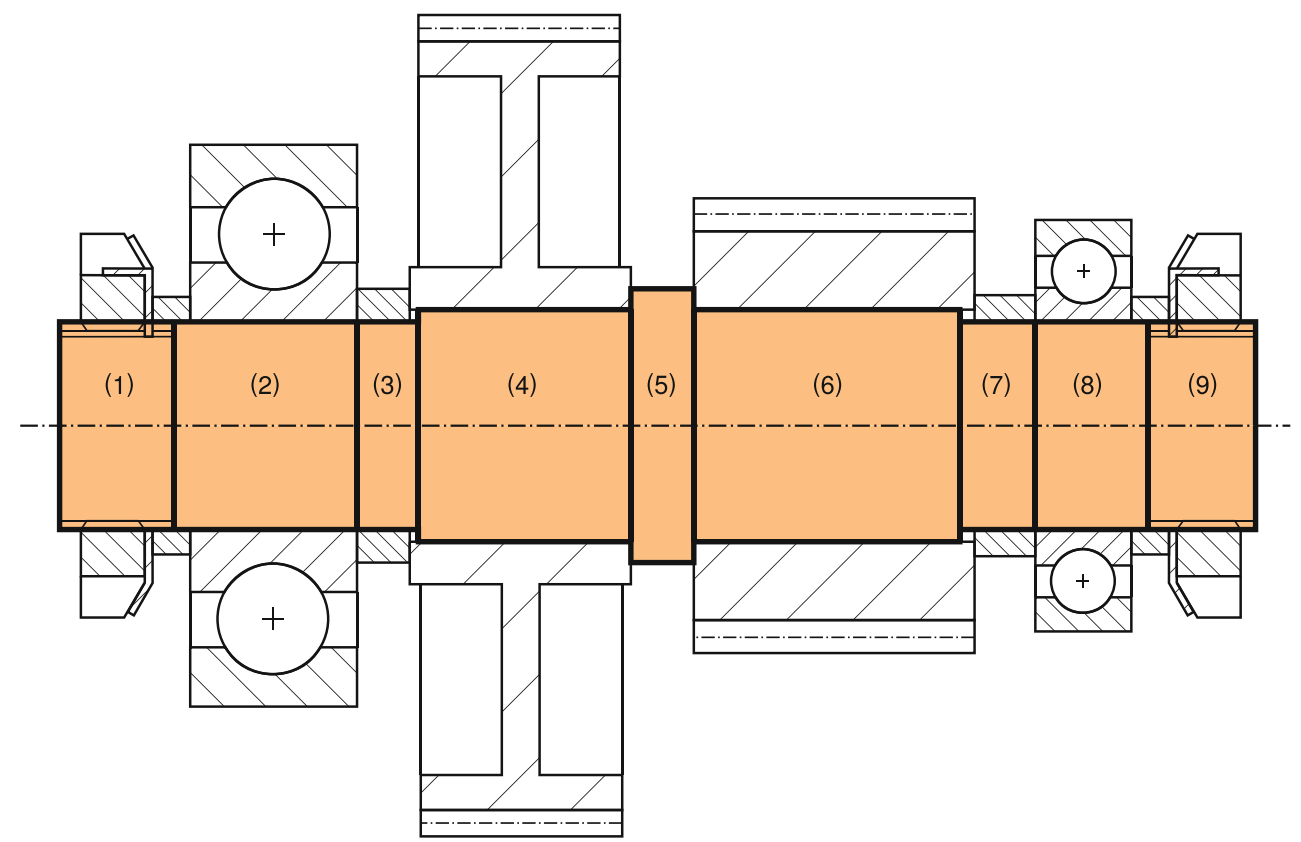


pinion is cut in the shaft. The bearing with the larger radial load (8) is chosen as the non-locating bearing.

\subsubsection{Wheel and pinion design}

In this study, the design of the wheel bodies is primarily used to estimate the mass of the gearbox and follows three basic design options: solid cylindrical, thin-walled web (lathed) and thin-walled web (forged) [29]. These experience-based parameterizations utilize quantities of the gear macro geometry and are therefore suitable for automation in the given context. Due to higher forces, pinions are realized as solid disks. Provided that a minimum hub thickness according to [21] can be maintained between the shaft diameter or the groove base and the tooth root, the pinion can be equipped with a shaft-hub connection.

\subsubsection{Spacing}

The lateral distance between gears is determined parametrically as a function of the circumferential speed and the module [21]. The same correlation is chosen for the lateral distance between the wheel and the bearing.

\subsection{Transfer towards an automated process}

The shaft model described in Sect. 2.1 was implemented in the existing program system GAP v5.1.0 [30]. The splitting of the total transmission ratio into several stages as well as the design of the gear toothing is based on the procedures described in publications by $[14,30,31]$. The object-oriented programming language Java is suitable for mapping the formulation of the shaft model as a sequence of different objects with mutual interaction. Digitized standard tables are read and processed as text-based input files in the program. Via the graphical user interface, settings can be chosen by the user regarding the desired type of positive torque transmission, axial locking element and rolling bearing type. An algorithm for automated design and layout of shafts, gears and bearings must essentially address two issues: How to design? and How to evaluate fitness?. The first problem is implemented by means of an objectoriented shaft model. Here, the shaft consists of several shaft sections (corresponding to the shaft skeleton), which interact with each other. Each section knows about the state (diameter and length) of its directly neighboring sections. According to the shaft skeleton, the choice of each diameter of a section determines the range of stepping $\boldsymbol{R}$ of its directly adjacent section (i.e. the minimum and maximum diameter value). By means of iterations over all shaft sections along a shaft, the desired relative structure of the shaft skeleton can thus be converted into an absolute contour. For this purpose, an adjustment of the diameter values is per- formed until a valid geometry is found (i.e. all diameters are within their specific range of stepping $\boldsymbol{R}$ ). Here, the section-specific boundary conditions (discrete value set $\mathcal{F}$, sufficient load capacity $\boldsymbol{S}$ ) are taken into account, since a sufficiently dimensioned machine element (shaft-hub connection, rolling bearing) must be found for each section. For shaft-hub connections, this is done roughly on the basis of the torque to be transmitted, for rolling bearings from the calculation of the expanded specified rating life. The necessary calculation of the bearing forces is carried out using RIKOR. All related lengths of shaft sections are then calculated according to the section parameterizations. Every iteration is followed by an update of the positions of the gear elements in GAP. After a first valid shaft geometry has successfully been derived, a strength assessment of the shaft at the notch points is conducted according to DIN 743 [12]. This step addresses the second of the above stated issues which the algorithm has to deal with. A calculation program called WELLNESS [16] which is connected to RIKOR is used in this step. The calculated notch safety factors are lead back into the design of the shaft geometry, so that a reduction of the relevant shaft diameters can be made in case of oversizing. This iterative procedure is repeated until a minimum of the objective function $z$ is found for each shaft section and, at the same time, all constraints are satisfied. Since individual section diameters can only be varied independently within certain limits, several iterations are always required until convergence. Due to the discrete set of values of available standard part diameters, it is not possible to adapt all notch safeties ideally to the specified minimum.

\section{Results and discussion}

The suitability of the shaft model for computer-aided automated design will be demonstrated by means of the design of an exemplary two-stage high-speed gear unit. The specifications and the boundary conditions for shaft, bearing and gear dimensioning are listed in Table 1. Model preparation only requires the presetting of these values in the GUI.

With the described design module, it was possible to find a converging and geometrically reasonable solution for the two-stage example gear unit. The calculation was completed on a computer with an Intel Core $17-8750 \mathrm{H}$ running at $2.20 \mathrm{GHz}$ using $16 \mathrm{~GB}$ of RAM after just a few minutes ( $\ll 5 \mathrm{~min}$ ). Compared to the conventional approach, the proposed model offers a significant time saving of several man-hours thanks to the automation of manual steps. The notch safety specifications for the design are met on each shaft as well as the calculated service lives of all rolling bearings exceed the target. A three-dimensional representation of the design result can be seen in Fig. 10. 
Table 1 Specifications for the example gear unit

\begin{tabular}{|c|c|c|}
\hline \multicolumn{3}{|l|}{ Gear unit } \\
\hline Input power & $P_{1}$ & $=90 \mathrm{~kW}$ \\
\hline Input speed & $n_{1}$ & $=13000 \mathrm{~min}^{-1}$ \\
\hline Gear ratio & $i$ & $=6$ \\
\hline \multicolumn{3}{|l|}{ Bearing } \\
\hline Probability of default & $n$ & $=10 \%$ \\
\hline Contamination factor & $\eta_{\mathrm{c}}$ & $=0.6$ \\
\hline Full load lifetime & $L_{n \mathrm{~h}}$ & $=900 \mathrm{~h}$ \\
\hline Oil temperature & $\vartheta$ & $=70 \circ \mathrm{C}$ \\
\hline Lubricant & & ISO-VG-150 \\
\hline Bearing arrangement & & Locating/non-locating \\
\hline Bearing type & & Ball and roller \\
\hline Shaft-hub connection & & Spline shaft \\
\hline Axial lock & & Circlip \\
\hline \multicolumn{3}{|l|}{ Toothing } \\
\hline Width/pitch diam. ratio & $\frac{b}{d_{1}}$ & $=0.7$ \\
\hline Overlap ratio & $\varepsilon_{\beta}$ & $=1.2$ \\
\hline Reference profile & & DIN 867 \\
\hline Profile shift & $x$ & DIN 3992 \\
\hline Pressure angle & $\alpha_{\mathrm{n}}$ & $=20 \circ$ \\
\hline Wheel body pinion & & Full cylinder \\
\hline Wheel body gear & & Thin-walled web \\
\hline \multicolumn{3}{|l|}{ Load factors } \\
\hline Application factor & $K_{\mathrm{A}}$ & $=1.35$ \\
\hline Dynamic factor & $K_{\mathrm{v}}$ & $=1.5$ \\
\hline Face load factor & $K_{\mathrm{H} \beta}$ & $=1.5$ \\
\hline Transverse load factor & $K_{\mathrm{H} \alpha}$ & $=1.1$ \\
\hline \multicolumn{3}{|l|}{ Safety factor } \\
\hline for pitting & $S_{\mathrm{Hmin}}$ & $=1.2$ \\
\hline for tooth breakage & $S_{\text {Fmin }}$ & $=1.5$ \\
\hline against fatigue of shaft & $S_{\mathrm{D}, \min }$ & $=1.5$ \\
\hline against yield of shaft & $S_{\mathrm{F}, \min }$ & $=1.5$ \\
\hline against crack of shaft & $S_{\mathrm{A}, \min }$ & $=1.5$ \\
\hline \multicolumn{3}{|l|}{ Materials } \\
\hline Shaft & & $50 \mathrm{CrMo} 4$ \\
\hline Gear & & $16 \mathrm{MnCr} 5$ \\
\hline
\end{tabular}

In this view, the machine elements are shown in an abstracted form with simplified geometric shapes. However, the selected machine elements are represented to scale by their main dimensions. The information about the designation of the selected standard parts, their dimensions and positions as well as the geometry of the notch points can be accessed via dialog windows. An exact reproduction of the gear shafts and machine elements can therefore be carried out directly in a CAD program, see Fig. 11 for the input shaft.

The calculated notch safeties according to DIN 743 for the given load case are plotted on this shaft in Fig. 12. Variant 1 represents the baseline design according to the specifications in Table 1. As explained in Sect. 2.1, in ad-

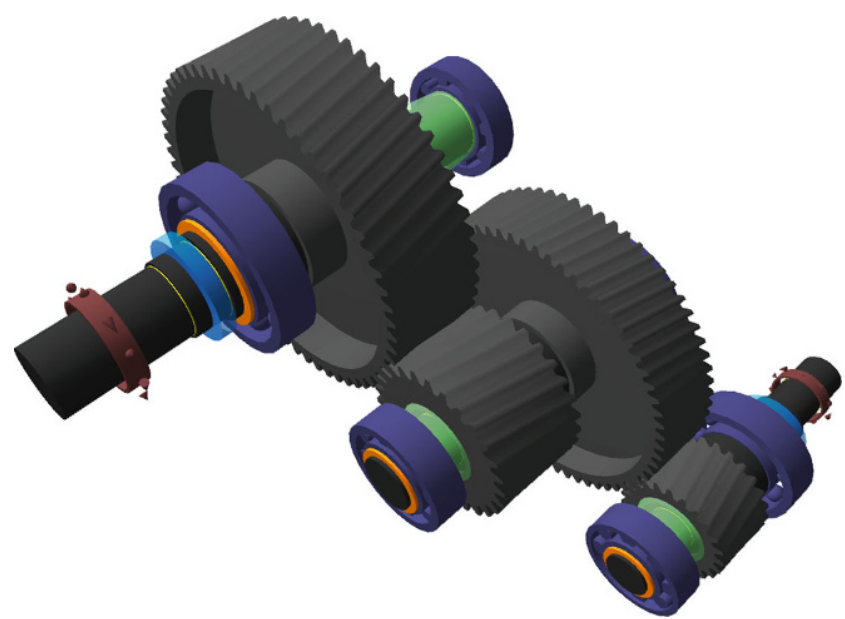

Fig. 10 3D representation of the designed gearbox with gears (grey), shafts (black), radial shaft seals (light blue), circlips (orange), bearings (dark blue) and sleeves (light green)

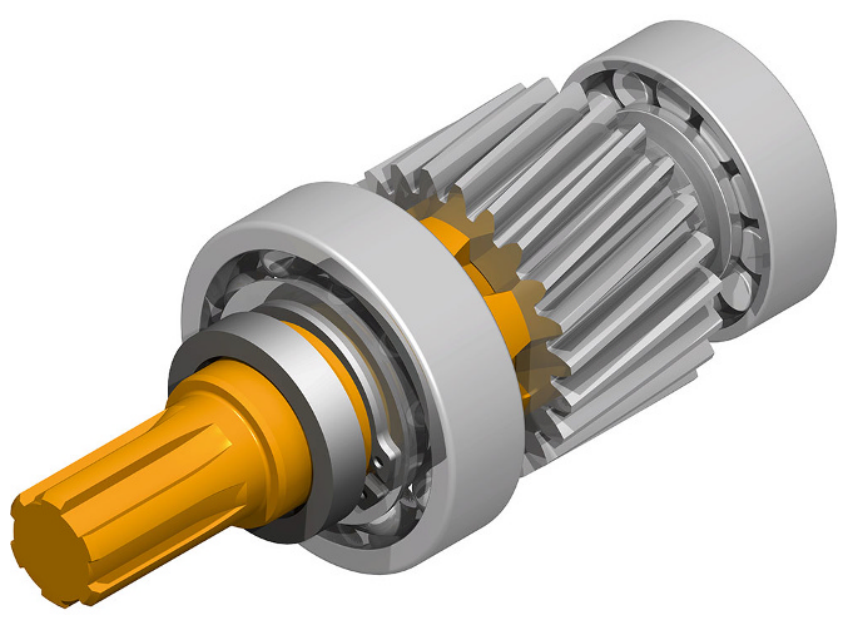

Fig. 11 Rendering of the designed input shaft. Selected elements: RWDR DIN 3760 - A25 × $35 \times 7$ [3], SKF 62/28 [33], SKF N 204 ECP [33]

dition to splined shaft connections and circlips, key connections and lock nuts are also taken into account in the model. On this basis, a parameter study was carried out. Its strength assessment results for the different variants are shown in Fig. 12. Since shaft geometries are slightly different, the data points are qualitatively aligned to the baseline shaft. For lock nuts, an additional notch is considered on the thread undercut between the lock nut and the rolling bearing.

For all variants, the notch safety factors against fatigue of the shaft are close to the target value at the first shaft section. The subsequent notches show a similar curve with safety factors increasing towards the middle of the shaft. The restriction to only discrete values for sealing rings and 


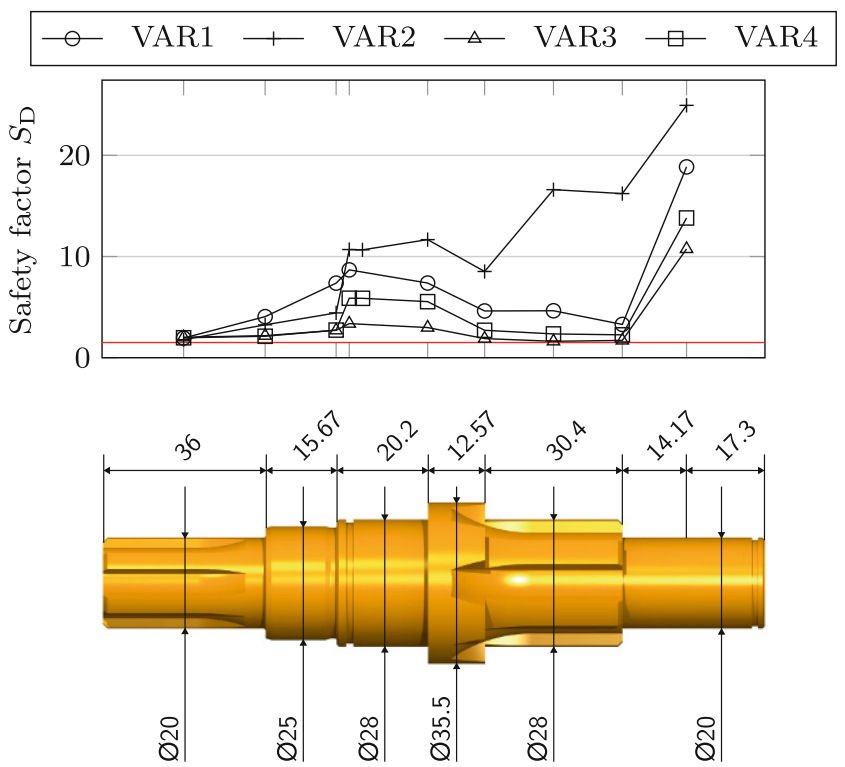

Fig. 12 Safety factor against fatigue fracture at notches of input shaft. Exact geometry representation (dimensions in mm) for VAR1 (spline and circlip), relative positioning for VAR2 (spline and lock nut), VAR3 (key and circlip) and VAR4 (key and lock nut). Values outside the diagram area are not displayed

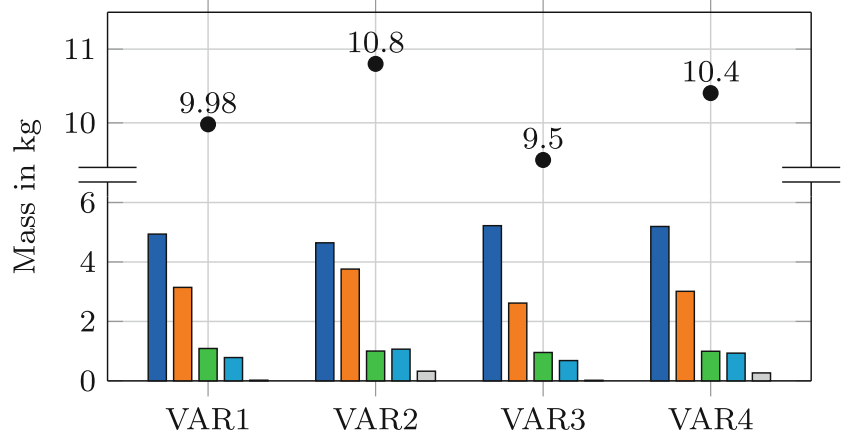

$$
\begin{aligned}
& \text { पuGears LuShafts LuBearings } \\
& \text { पuSleeves QuAx.locks } \boldsymbol{0}_{\text {Total mass }}
\end{aligned}
$$

Fig. 13 Mass proportions of different variants: VAR1 (spline and circlip), VAR2 (spline and lock nut), VAR3 (key and circlip) and VAR4 (key and lock nut)

bearings prevents an ideally homogeneous stress distribution along the shaft contour. In addition, the dimensioning is also affected by different notch effects of the various notch shapes. Overall, the highest safety factors are observed for VAR2 (spline and lock nut). Due to insufficient residual hub thickness on the pinion, the toothing is cut into the shaft in this variant. In the design, the specified gear material with lower yield strength and fatigue limit is then used for the entire shaft what typically leads to larger shaft diameters. This variant therefore has the highest total shaft mass.

It was observed that the intermediate shafts can be designed much more homogeneously in terms of stress con- centration due to the absence of external torque in-/ or output and sealing rings.

Fig. 13 shows the resulting mass proportions of the different machine elements in the calculated total gear unit mass for all variants.

By using circlips, the lowest shaft masses can be achieved. This can be attributed to the shorter axial length of the section of a circlip. In contrast to the variant with lock nuts, no large diameter step has to be maintained for manufacturing the groove of the locking plate.

In the same way, the influence of bearing types on the total mass and mass distribution can be investigated. All previously discussed variants use cylindrical roller bearings for the non-locating bearing and deep groove ball bearings for the locating bearing. Fig. 14 compares these results with the results obtained using deep groove ball bearings exclusively.

While the gear and shaft masses remain largely unchanged, the bearing mass increases significantly. Comparatively heavy deep groove ball bearings are required in particular on the intermediate shaft with the high radial load. At the same time, using only deep groove ball bearings does not offer weight saving potential for input and output shafts at least in this case.

The previous variants assumed a planar arrangement of the shafts, but a compact design typically offers additional potential for weight saving. However, a compact design affects the possible mounting conditions. A parameter variation on the overall gearbox level was carried out by modifying the spatial positions of the gearbox shafts. The spatial angle $\varphi$ between the shafts of the first stage and the horizontal serves as a variation parameter. Fig. 15 shows the calculated mass fractions of different variants. Due to the lack of a detailed housing model, the change in housing mass cannot be quantified.

Even without taking the housing mass directly into account, an influence of the spatial angle on the resulting gear unit mass can be detected. This can be attributed to the fact that the radial load on the bearings of the intermediate shaft is significantly reduced, while the radial load on the input and output shafts increases slightly. As a result, lighter rolling bearings can be selected on the intermediate shaft, which is why the bearing masses in Fig. 15 decrease with an increasing angle. In this case, the bearings on the input and output shafts, which are slightly oversized anyway, can accommodate the additional load with the same size. Compared to the planar arrangement, the spatially shifted tooth meshes lead to a different bending deformation of the intermediate shaft. In the present case, the lower bending deformation has a positive effect on the face load factor $K_{\mathrm{H} \beta}$, which is continuously evaluated in RIKOR during the iteration and fed back into the gear design. As a consequence, the gear mass decreases with an increasing angle since the 


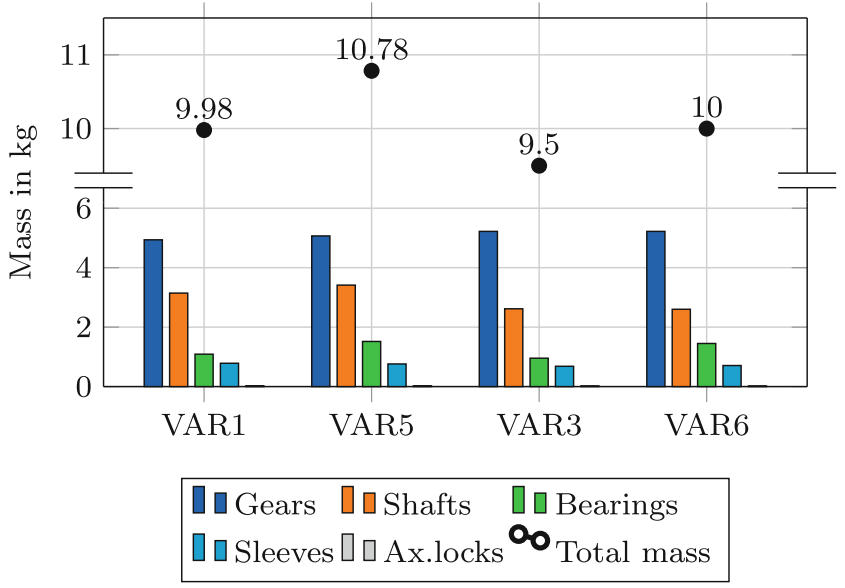

Fig. 14 Mass proportions of different variants: VAR1 (spline/circlip), VAR5 (spline/circlip/deep groove ball bearings), VAR3 (key/circlip) and VAR6 (key/circlip/deep groove ball bearing)

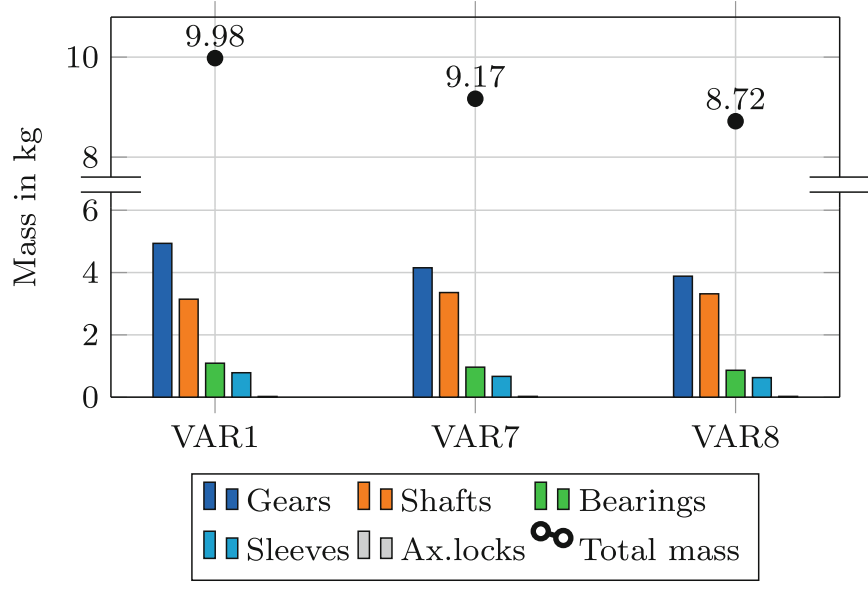

Fig. 15 Mass proportions of different variants: VAR1 $(\varphi=0 \circ)$, VAR7 $(\varphi=45 \circ)$, VAR8 $(\varphi=75 \circ)$. All variants: spline and circlip

gear dimensions have slightly changed (tooth width and module of the first stage). The chosen wheel body parameterization herewith provides lower rim and web thickness, which leads to a lower weight of the gear set. The mass of shafts increases for the variants with spatial angles greater than zero, since here the input shafts are designed with cutin teeth. Hence, the wheel body mass is included in the shaft mass.

\section{Conclusion}

The proposed design method enables the integration of design experience with regard to the shaft-bearing system into the overall transmission design process. In addition to iterative optimization, the automated feedback of analysis steps simultaneously provides computational proof of compliance with the required safeties. Within a few minutes, a detailed design of the shaft-bearing system that is basically ready for production can be generated. The integration of updatable and adaptable standard tables ensures practical relevance. The efficiency of the method was demonstrated by means of a case study. As shown, concept studies can be accelerated significantly and evaluated on the basis of a more comprehensive database.

With regard to general applicability of the model to any system, however, further development is still needed. At the present time, simple helical gear stages can be modeled in which at least the geometric interpenetration of adjacent rolling bearings and gears is checked and prevented. In the case of multiple, arbitrarily arranged stages of a gear system, the complexity increases rapidly due to increasing cross influences. Designs such as planetary stages or bevel gear stages require their own specific shaft models, which have yet to be developed. However, even the existing model for helical gear stages still offers extensive development potential. Further development of the formulation of the optimization problem (currently mass minimization while maintaining service life and notch safety) to take account of other boundary conditions such as limiting maximum shaft deflection appears to be expedient. With regard to the supported bearing type, the most complex variant in terms of design was selected with the implementation of a locating/non-locating bearing arrangement, but the design of adjusted or floating bearing arrangements and consideration of other bearing types must also be implemented to increase practical relevance. In this respect, an evaluation function is also required for all those design aspects that previously had to be specified by the user. For the automated selection of the most suitable design variant, for example, a cost function for rolling bearings and rolling bearing arrangements or the evaluation of the manufacturing effort of axial locking devices would be conceivable.

\section{Declarations}

- Funding: Not applicable

- Availability of data and material: The datasets generated and analyzed during the current study are available from the corresponding author on reasonable request.

- Code availability: Software application with custom code.

Conflicts of interest On behalf of all authors, the corresponding author states that there is no conflict of interest.

Funding Open Access funding enabled and organized by Projekt DEAL.

Open Access This article is licensed under a Creative Commons Attribution 4.0 International License, which permits use, sharing, adaptation, distribution and reproduction in any medium or format, as long as 
you give appropriate credit to the original author(s) and the source, provide a link to the Creative Commons licence, and indicate if changes were made. The images or other third party material in this article are included in the article's Creative Commons licence, unless indicated otherwise in a credit line to the material. If material is not included in the article's Creative Commons licence and your intended use is not permitted by statutory regulation or exceeds the permitted use, you will need to obtain permission directly from the copyright holder. To view a copy of this licence, visit http://creativecommons.org/licenses/by/4. $0 /$.

\section{References}

1. DIN 748-1:1970-01 (1970) Zylindrische Wellenenden - Teil 1: Abmessungen, Nenndrehmomente

2. DIN 323-1:1974-08 (1974) Normzahlen und Normzahlreihen - Teil 1: Hauptwerte, Genauwerte, Rundwerte

3. DIN 3760:1996-09 (1996) Radial-Wellendichtringe

4. DIN 13-1:1999-11 (1999) Metrisches ISO-Gewinde allgemeiner Anwendung: Teil 1: Nennmaße für Regelgewinde

5. DIN 5466-1:2000-10 (2000) Tragfähigkeitsberechnung von Zahnund Keilwellen- Verbindungen - Teil 1: Grundlagen

6. DIN 509:2006-12 (2006) Technische Zeichnungen - Freistiche Formen, Maße

7. DIN 981:2009-06 (2009) Wälzlager - Nutmuttern

8. DIN ISO 281:2010-10 (2010) Wälzlager - Dynamische Tragzahlen und nominelle Lebensdauer

9. DIN 471:2011-04 (2011) Sicherungsringe (Halteringe) für Wellen - Regelausführung und schwere Ausführung

10. DIN 5406:2011-04 (2011) Wälzlager - Muttersicherungen; Sicherungsblech, Sicherungsbügel

11. DIN 6892:2012-08 (2012) Mitnehmerverbindungen ohne Anzug Passfedern - Berechnung und Gestaltung

12. DIN 743:2012-12 (2012) Tragfähigkeitsberechnung von Wellen und Achsen

13. DIN 76-1:2016-08 (2016) Gewindeausläufe und Gewindefreistiche - Teil 1: Für Metrisches ISO-Gewinde nach DIN 13-1

14. Bansemir G (2013) Konstruktionsleitsystem für den durchgängig rechnerbasierten Zahnradgetriebeentwurf. Dissertation, Technische Universität München

15. Dyla A (2002) Modell einer durchgängig rechnerbasierten Produktentwicklung. Dissertation, Technische Universität München

16. Fingerle A, Prölß M, Albert B, Otto M, Hagemann T, Stahl K, Schwarze H (2018) Durchgängige Berechnung gleitgelagerter Welle-Lager-Systeme. FVA 668 II, Heft 1282

17. Fromberger M, Otto M (2016) Erweiterung STplus Abschlussbericht: Erweiterung FVA-Stirnradprogramm STplus. FVA 241/XI, Heft 1198
18. FVA Software \& Service (2021) FVA-Workbench. https://www. fva-service.de/en/software/. Accessed 7 Mar 2021

19. Hirt M, Lindemann U (1984) CAD in der Antriebstechnik - Optimieren und Gestalten von Stirnradgetrieben. Antriebstechnik 23(8):35-38

20. Hirt M, Weiss T (1987) New methods of integrated computerized design and manufacturing of high speed gearing. In: AGMA (ed) AGMA 1987 Fall Technical Meeting, vol 87FTM16

21. Höhn BR (2014) Zahnradgetriebe. In: Grote KH, Feldhusen J, Dubbel H (eds) Dubbel. Springer Vieweg, Berlin, pp 563-602

22. Holder K, Rudolph S, Stetter R, Salander C (2019) Automated requirements-driven design synthesis of gearboxes with graph-based design languages using state of the art tools. Forsch Ingenieurwes 83(3):655-668

23. Karayel D, Ozkan SS, Vatansever F (2013) Integrated knowledgebased system for machine design. Adv Mech Eng. https://doi.org/ $10.1155 / 2013 / 702590$

24. KISSsoft (2021) KISSsoft Elements. https://www.kisssoft.com/ en/products/product-overview/kisssoftr-elements. Accessed $7 \mathrm{Mar}$ 2021

25. KISSsoft (2021) KISSsys Elements. https://www.kisssoft.com/ en/products/product-overview/kisssys-elements. Accessed 7 Mar 2021

26. MDESIGN (2021) Products. https://www.mdesign.de/en/products/. Accessed 7 Mar 2021

27. Naunheimer H, Bertsche B, Lechner G, Ryborz J (2007) Fahrzeuggetriebe: Grundlagen, Auswahl, Auslegung und Konstruktion, 2nd edn. Springer, Berlin, Heidelberg

28. Neubauer B, Weinberger U, Otto M (2016) LAPLASn. FVA 571 II, Heft 1997

29. Niemann G, Winter H (2003) Maschinenelemente: Band 2: Getriebe allgemein, Zahnradgetriebe - Grundlagen, Stirnradgetriebe, 2nd edn. Springer, Berlin, Heidelberg

30. Parlow J, Otto M (2016) Erweiterung Getriebeauslegungsprogramm IV. FVA 421 IV, Heft 1199

31. Parlow JC (2016) Entwicklung einer Methode zum anforderungsgerechten Entwurf von Stirnradgetrieben. Dissertation, Technische Universität München

32. Romax (2021) Software. https://romaxtech.com/software/. Accessed 7 Mar 2021

33. SKF Gruppe (2014) Wälzlager, 2nd edn.

34. Smart Manufacturing Technology (2021) MASTA. https://www. smartmt.com/cae-software/masta/overview/. Accessed 7 Mar 2021

35. Wittel H, Jannasch D, Voßiek J, Spura C (2017) Roloff/Matek Maschinenelemente: Normung, Berechnung, Gestaltung, 23rd edn. Springer Vieweg, Wiesbaden 